\title{
Microscopic pulmonary tumour embolism: An unusual presentation of thymic carcinoma
}

\author{
Brita L Sperling¹, Donald W Cockcroft MD FRCPC ${ }^{2}$, \\ Rajni Chibbar MBBS FRCPC ${ }^{1}$
}

BL Sperling, DW Cockcroft, R Chibbar. Microscopic pulmonary tumour embolism: An unusual presentation of thymic carcinoma. Can Respir J 2002;9(5):347-350.

The present report describes the first reported case of microscopic pulmonary tumour embolism (MPTE) from thymic carcinoma. The carcinoma was discovered during an autopsy in a 55-year-old man who had undergone surgery for a pilonidal sinus two weeks before presentation. Pulmonary thromboembolism was suspected. This case was unusual because MPTE has never before been associated with thymic carcinoma, MPTE was the first clinical indication of an occult malignancy, and the clinical presentation was that of sudden onset of dyspnea associated with acute cor pulmonale. The cause of death was determined to be hypoxia secondary to extrinsic compression of the right pulmonary artery and extensive tumour emboli in the small arteries, arterioles and venules of the pulmonary parenchyma. A review of the clinical presentation and diagnosis of MPTE is included.

Key Words: Cor pulmonale; Microscopic pulmonary tumour embolism; Thymic carcinoma

\section{L'embolie microscopique d'une tumeur pulmonaire : Présentation inhabituelle d'un carcinome thymique}

RÉSUMÉ : Le présent rapport décrit le premier cas déclaré d'embolie miscroscopique d'une tumeur pulmonaire (EMTP) causée par un carcinome thymique. Le carcinome a été découvert à l'autopsie d'un homme de 55 ans qui avait subi l'opération d'un kyste pilonidal deux semaines avant de se présenter. Une thromboembolie pulmonaire était présumée. Ce cas était inhabituel car l'EMTP constituait le première indication clinique de malignité occulte, et la présentation clinique en était une de dyspnée d'apparition soudaine associée à un cor pulmonare aigu. La cause du décès a été déterminée comme une hypoxie secondaire à une compression extrinsèque de l'artère pulmonaire droite et à une embolie tumorale étendue dans les petites artères, les artérioles et les vénules du parenchyme pulmonaire. L'analyse de la présentation clinique et du diagnostic d'EMTP est incluse.

${ }^{1}$ Department of Pathology and ${ }^{2}$ Department of Internal Medicine, University of Saskatchewan, Royal University Hospital, Saskatoon, Saskatchewan Correspondence: Dr Rajni Chibbar, Department of Pathology, University of Saskatchewan, 103 Hospital Drive, Royal University Hospital,

Saskatoon, Saskatchewan S7N OW8. Telephone 306-249-2248, fax 306-655-2223,e-mail chibbarr@sdh.sk.ca 
$M$ icroscopic pulmonary tumour embolism (MPTE) is an underdiagnosed pathology that is a frequent cause of morbidity and mortality in patients with cancer (1-3). Most patients with MPTE have an established and often metastatic malignancy, the most common of which include stomach, breast, lung, prostate and pancreatic cancer, hepatocellular carcinoma, and choriocarcinoma (4). MPTE is rarely the first clinical sign of cancer. The most common presenting complaint of patients with MPTE is subacute dyspnea (1-5).

In the present paper, we describe a patient who had a primary thymic carcinoma with MPTE. This case is unusual for three reasons. First and most important, to our knowledge, it is the first reported case of MPTE associated with thymic carcinoma. Second, MPTE was the first clinical sign of the malignancy. Finally, the patient presented with acute dyspnea associated with acute cor pulmonale.

\section{CASE PRESENTATION}

A 55-year-old, previously healthy man presented with a four-day history of progressive shortness of breath that began suddenly. He had a new cough productive of brown sputum. He denied any chest pain. He had a smoking history of 60 pack-years, but nothing to suggest chronic obstructive pulmonary disease. He had undergone surgery for a pilonidal sinus two weeks previously and had thus been relatively immobile. Pulmonary embolism was considered to be highly possibile.

On physical examination, the patient's blood pressure was $93 / 70 \mathrm{mmHg}$, his pulse was 140 beats/min, his respiratory rate was 30 breaths/min and his temperature was $37.4^{\circ} \mathrm{C}$. His oxygen saturation on room air was $82 \%$. He had quiet breath sounds and inspiratory crackles bilaterally, and his heart sounds were normal but decreased. His jugular venous pressure was slightly elevated, and his legs and feet

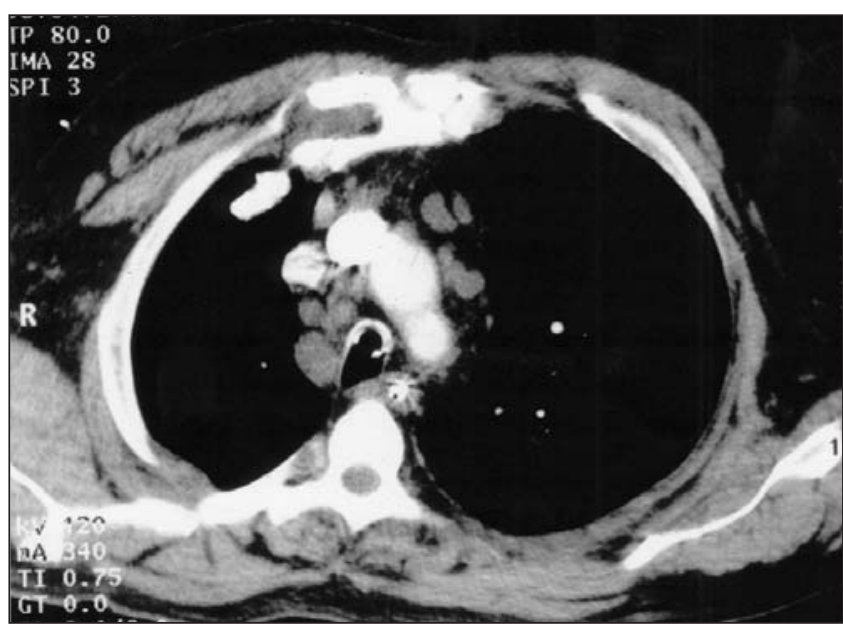

Figure 1) Chest computerized tomography scan demonstrating multiple enlarged lymph nodes in the anterior mediastium, the aortic pulmonary window, and the pretracheal, paratracheal and subcarinal regions, as well as increased soft tissue adjacent to the right main stem bronchus and right lower lobe bronchus were poorly perfused, with weak peripheral pulses. He had no peripheral edema or calf tenderness.

A chest roentgenogram demonstrated patchy consolidation and pleural effusion of the right lung, cardiomegaly, and mediastinal and left hilar lymphadenopathy. An electrocardiogram (ECG) showed tachycardia, as well as new features compared with an ECG performed two weeks previously, including a right bundle branch block, and symmetrical inversion of T waves in leads V1 to V4, II, III and aVF. His white blood cell count was elevated at $12 \times 10^{9} / \mathrm{L}$, his platelet count was $129 \times 10^{9} / \mathrm{L}$, his potassium level was low at $3.1 \mathrm{mmol} / \mathrm{L}$, and his blood urea nitrogen and creatinine levels were elevated at $11.7 \mathrm{mmol} / \mathrm{L}$ and $172 \mu \mathrm{mol} / \mathrm{L}$, respectively.

High flow oxygen therapy, intravenous fluids and heparin infusion were commenced; however, despite an initial rise to $96 \%$, his oxygen saturation had dropped to $86 \%$ by the next morning. An analysis of his arterial blood gases showed a $\mathrm{pH}$ of 7.48, a partial pressure of oxygen of $47 \mathrm{mmHg}$, a partial pressure of carbon dioxide of $26 \mathrm{mmHg}$ and a bicarbonate concentration of $17 \mathrm{mEq} / \mathrm{L}$. A pulmonary nuclear perfusion scan did not demonstrate discrete segmental or subsegmental perfusion defects, making the probability of pulmonary thromboembolic disease low (the patient was unable to tolerate the ventilation study). A chest computer tomography scan (Figure 1) using a dedicated pulmonary embolism protocol demonstrated multiple enlarged lymph nodes in the anterior mediastium, aortic pulmonary window, and pretracheal, paratracheal and subcarinal regions, as well as increased soft tissue adjacent to the right main stem bronchus and right lower lobe bronchus. These findings appeared to be representative of a lymphoma or metastatic disease. The chest computer tomography scan also showed compression of the right pulmonary artery at the level of the main stem bronchus, most likely because of an extrinsic mass. A pulmonary angiogram was not completed because there was a very high likelihood of malignancy.

The patient's oxygen saturation continued to drop, and the decision was made to intubate and ventilate him. However, he continued to deteriorate and died two days after his admission.

An autopsy revealed an $11 \mathrm{~cm} \times 7 \mathrm{~cm} \times 5 \mathrm{~cm}$ irregular, lobular mass in the anterior mediastinum, surrounding the trachea, right main bronchus, upper part of the thoracic aorta, the right pulmonary artery, the aortic arch, a portion of the superior vena cava and the middle esophagus. There was a second $15 \mathrm{~cm} \times 15 \mathrm{~cm} \times 5 \mathrm{~cm}$ lobular para-aortic mass just above and around the bifurcation of the common iliac arteries. There were no masses in the lungs, gastrointestinal tract, liver, pancreas, prostate, kidney or testicles (gross and microscopic). The right ventricle was dilated without hypertrophy.

Microscopic examination of the mediastinal mass showed a lobulated lesion composed of discohesive cells with enlarged, vesicular nuclei and prominent nucleoli (Figure 2). Numerous tumour giant cells and mitotic figures were present. Extensive areas of tumour necrosis and lym- 


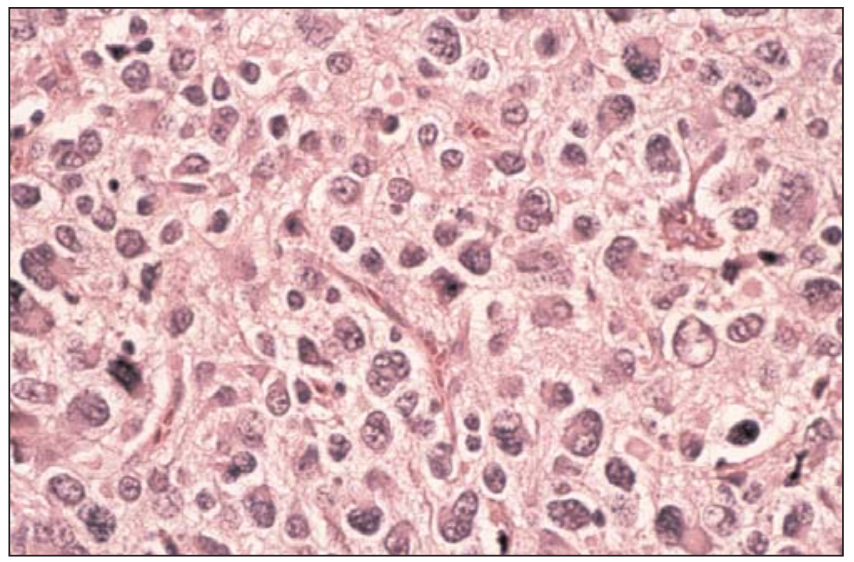

Figure 2) High power magnification of the mediastinal tumour, showing discohesive cells with nuclear enlargement, hyperchromatism and pleomorphism. (Hematoxylin and eosin stain, original magnification $\times 320$ )

phovascular invasion were present. There was microscopic invasion of the capsule and adjacent adipose tissue. Sections from the para-aortic mass showed matted expanses of lymph nodes, with almost complete replacement of lymphoid tissue by lobules of tumour cells.

Immunohistochemical analysis showed that the neoplastic cells were positive for high molecular weight keratin (HMWK), an epithelial cell marker, and CD-5, a type of receptor molecule that signals cell growth in $\mathrm{T}$ cells. These findings support a diagnosis of thymic carcinoma, because the lesional cells from thymic carcinoma were positive for HMWK and CD-5 (6). Neoplastic cells in most thymomas and carcinomas of nonthymic origins are negative for coexpression of HMWK and CD-5. With additional immunohistochemical analysis, the neoplastic cells were found to be negative for epithelial membrane antigen, smooth muscle antigen, S-100, CD-45, vimentin, placental alkaline phosphatase and alpha-fetoprotein. These findings rule out the diagnosis of a metastatic melanoma, lymphoma, sarcoma or metastatic testicular tumour, and support the diagnosis of undifferentiated (anaplastic) thymic carcinoma with metastasis to mediastinal and para-aortic lymph nodes.

Sections from the lungs showed multiple microscopic tumour emboli distributed diffusely within pulmonary arteries, arterioles, pulmonary septal capillaries, venules and veins, with variable occlusion of the vascular lumens (Figure 3). Numerous lymphatic vessels were also filled by tumour emboli.

The cause of death was determined to be hypoxia secondary to extrinsic compression of the right pulmonary artery and numerous tumour emboli in vessels of the pulmonary parenchyma.

\section{DISCUSSION}

Pulmonary embolism can develop from either detached thrombi or tumours in patients with cancer. Pulmonary tumour emboli may be large or microscopic. MPTE, though a frequent cause of morbidity and mortality in patients with

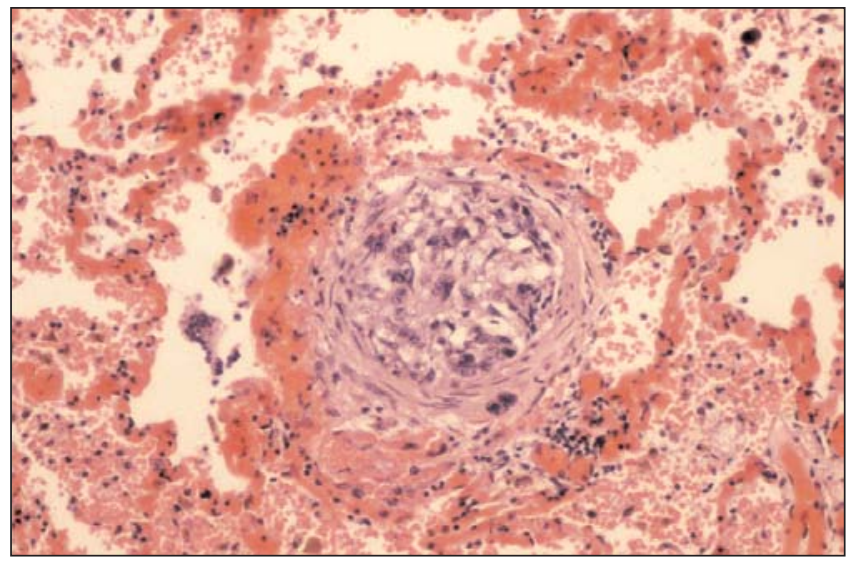

Figure 3) A muscular pulmonary artery within the lung parenchyma showing a microscopic tumour embolus with complete occlusion of the vessel lumen. (Hematoxylin and eosin stain, original magnification $\times 150$ )

cancer, is not frequently diagnosed antemortem (7). Based on autopsy studies, the incidence of MPTE in patients with solid neoplasms ranges from $2 \%$ to $26 \%$ and is the cause of death in up to $14 \%$ of these cases $(2,7,8)$. MPTE has been reported in patients with breast, lung, prostate, pancreatic, gastric, gallbladder, bladder, colorectal, skin, cervical and uterine cancer, hepatocellular carcinoma, and choriocarcinoma $(4,5)$. The present case is, therefore, unique because, to our knowledge, it is the first reported thymic carcinoma associated with MPTE.

Thymic carcinoma is a rare tumour associated with a poor prognosis. The most common presenting symptoms of thymic carcinoma - chest pain, cough and dyspnea - are secondary to tumour invasion or compression of the airways and adjacent lung, and are not due to MPTE as presently described. In an analysis of 19 clinicopathological studies of thymic carcinoma (9), 52\% of patients developed metastases. Although metastases to the lung parenchyma are not unusual in thymic carcinoma, microscopic tumour embolism in the pulmonary vessels from thymic carcinoma has never before been reported.

MPTE is rarely the first clinical sign of malignancy. It usually occurs in patients with an established and frequently metastatic tumour (4). A few cases in the literature to date report MPTE as the first indication of cancer $(4,10,11)$. These malignancies were of the liver, pancreas, stomach, ovaries and breast.

The most common presenting symptom of patients with MPTE is subacute cor pulmonale associated with progressive dyspnea ranging from weeks to months in duration before diagnosis or death $(1,3,4,8)$. There are few reports of patients presenting with acute cor pulmonale who have sudden onset of dyspnea and rapid development of respiratory failure (12-14). In the present case, the patient's shortness of breath came on suddenly and lasted for four days before admission. Once in the hospital, he rapidly deteriorated, required mechanical ventilation and died within two days. Thus, his cumulative symptom duration was only six days. 
Classically, the physical examination of patients with MPTE reveals signs of pulmonary hypertension: tachycardia, tachypnea, normal lung auscultation, increased jugular venous pressure and a loud pulmonic second heart sound. Usually, an ECG shows nonspecific changes, with a sinus tachycardia (7). A right ventricular strain pattern was noted in our patient, likely due to the increased right ventricular systolic pressure secondary to pulmonary hypertension. Analysis of blood gases typically reveals hypoxemia (7). The tumour cell embolization of pulmonary circulation causes unrelenting respiratory distress out of proportion to the physical findings in the heart and lungs.

The histological changes of the vascular bed are primarily intra-arterial; therefore, the roentogenographic findings are either absent or meager (2). Normal-appearing lungs on a chest radiograph in association with severe respiratory symptoms is typical of MPTE. There is usually no marked pulmonary hypertension or cardiopulmonary functional derangements until $60 \%$ to $80 \%$ of the pulmonary arterial bed has been occluded by the tumour emboli.
Ventilation-perfusion scans may demonstrate subsegmental perfusion defects without ventilatory defects (15). Pulmonary angiography usually shows no evidence of emboli, but may demonstrate slowed filling, tortuosity or pruning of small peripheral vessels (16).

Any malignancy may be a source of pulmonary tumour emboli. On the other hand, microscopic pulmonary emboli may result from thrombophlebitis in the lower extremities, especially in patients with prolonged bed rest. The determination of the origin of pulmonary emboli has therapeutic implications, because anticoagulation is indicated in thrombotic emboli but not in tumour emboli. Furthermore, with advances in chemotherapy, MPTE may be treatable if diagnosed correctly antemortem (7).

To confirm the diagnosis, tissue must be obtained by open lung biopsy or transbronchial biopsy. A recently described, less invasive procedure using pulmonary microvascular cytology of blood samples obtained from a Swan Ganz catheter may be useful in the detection of tumour cell embolization (17).

\section{REFERENCES}

1. Veinot JP, Ford SE, Price RG. Subacute cor pulmonale due to tumour embolization. Arch Pathol Lab Med 1992;116:131-4.

2. He XW, Tang YH, Luo, ZQ, et al. Subacute cor pulmonale due to tumour embolization to the lungs. Angiology 1989;40:11-7.

3. Lambert-Jensen P, Mertz H, Nyvad O, et al. Subacute cor pulmonale due to microscopic pulmonary tumour cell embolization. J Intern Med 1994;236:597-8.

4. Montero A, Vidaller A, Mitjavila F, et al. Microscopic pulmonary tumour embolism and subacute cor pulmonale as the first clinical signs of cancer. Acta Oncol 1999;38:1116-8.

5. Kane RD, Hawkins HK, Miller JA, Noce PS. Microscopic pulmonary tumour emboli associated with dyspnea. Cancer 1975;36:1473-82.

6. Hishima T, Fukayama M, Fujisawa M, et al. CD5 expression in thymic carcinoma. Am J Pathol 1994;145:268-75.

7. Schriner RW, Ryu JH, Edwards WD. Microscopic pulmonary tumor embolism causing subacute cor pulmonale: a difficult antemortem diagnosis. Mayo Clin Proc 1991;66:143-8.

8. Soares FA, Magnani Landell GA, Mello De Oliveira RP. A prospective study of the morphological aspects of tumor involvement of the pulmonary vessels. Pathology 1992;24:150-4.

9. Chung DA. Thymic carcinoma: analysis of nineteen clinicopathological studies. Thorac Cardiovasc Surg 2000;48:114-9.

10. Gajdos C, Nierman DM, Moqtaderi FF, et al. Microscopic pulmonary tumour emboli: An unusual presentation of breast cancer. Breast J 2000;6:273-5.

11. Kuraki T, Kobayashi H, Nagata N, et al. Pulmonary tumour embolism caused by asymptomatic gastric cancer. Nihon Kyobu Shikkan Gakkai Zasshi 1997;35:641-2. (Abst)

12. Odeh M, Oliven A, Misselevitch I, et al. Acute cor pulmonale due to tumour cell microemboli. Respiration 1997;64:384-7.

13. Domanski MJ, Cunnion RE, Fernicola DJ. Fatal cor pulmonale caused by extensive tumour emboli in the small pulmonary arteries without emboli in the major pulmonary arteries or metastases in the pulmonary parenchyma. Am J Cardiol 1993;72:233-4.

14. Arisawa C, Fujii Y, Higashi Y, et al. Acute respiratory failure resulting from diffuse microscopic pulmonary tumour emboli by bladder cancer: a case diagnosed at autopsy. Hinyokika Kiyo 1993;39:475-8. (Abst)

15. Crane R, Rudd TG, Dail D. Tumour microembolism: pulmonary perfusion pattern. J Nucl Med 1984;25:877-80.

16. Rawlinson J, Ackery D. Microscopic tumour embolization: an unusual cause of ventilation-perfusion mismatch. $\mathrm{Br} \mathrm{J}$ Radiol 1988;61:956-7.

17. Masson RG, Ruggieri J. Pulmonary microvascular cytology: a new diagnostic application of the pulmonary artery catheter. Chest 1985;88:908-14. 


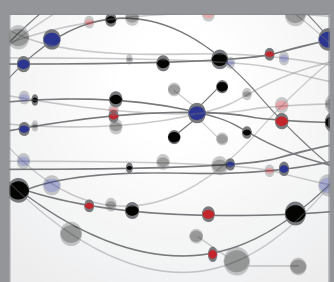

The Scientific World Journal
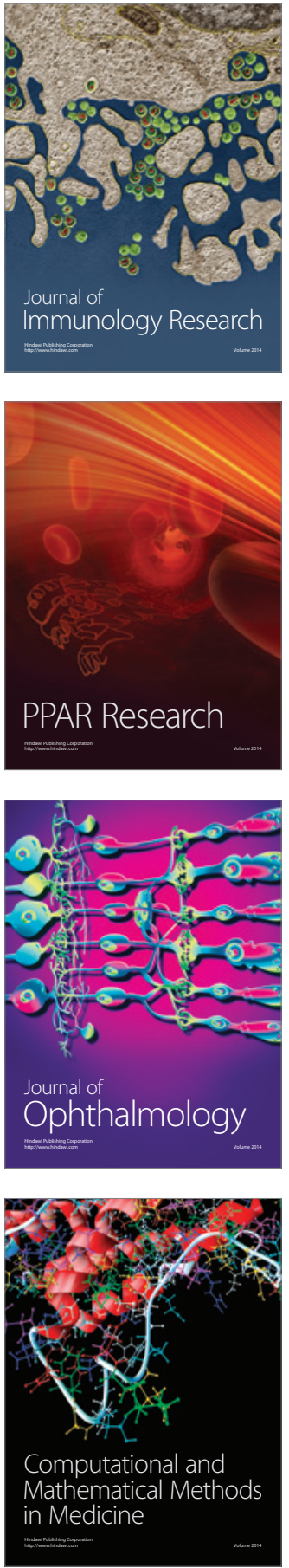

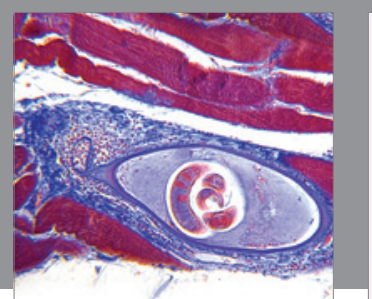

Gastroenterology Research and Practice

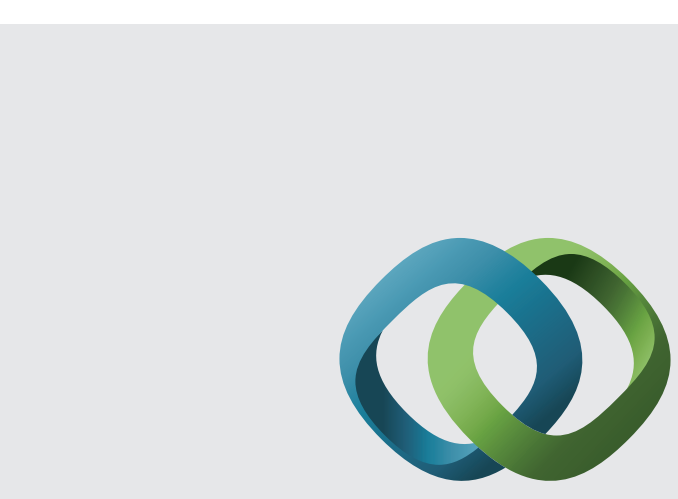

\section{Hindawi}

Submit your manuscripts at

http://www.hindawi.com
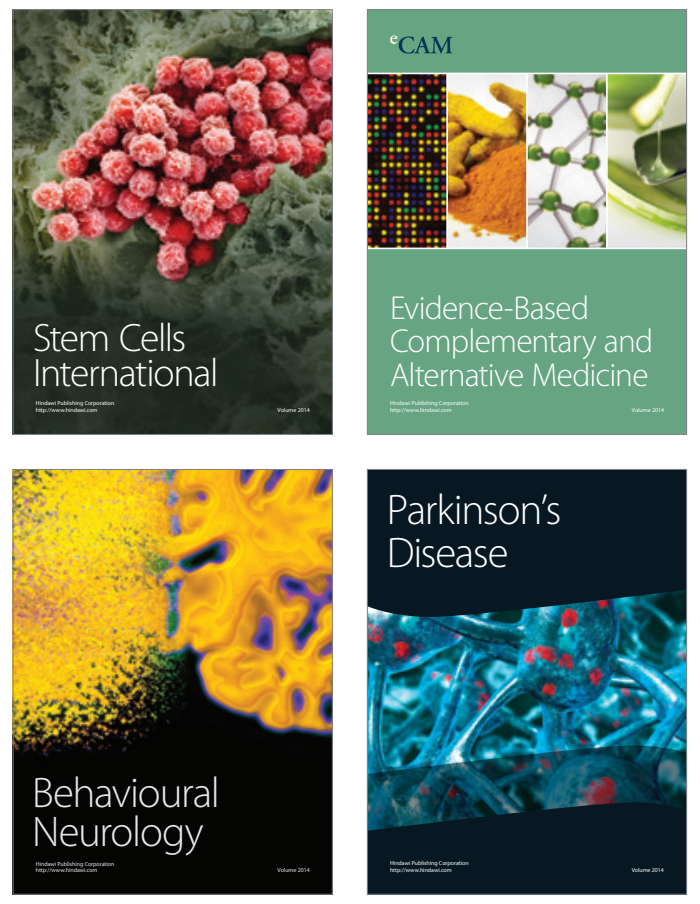


Disease Markers
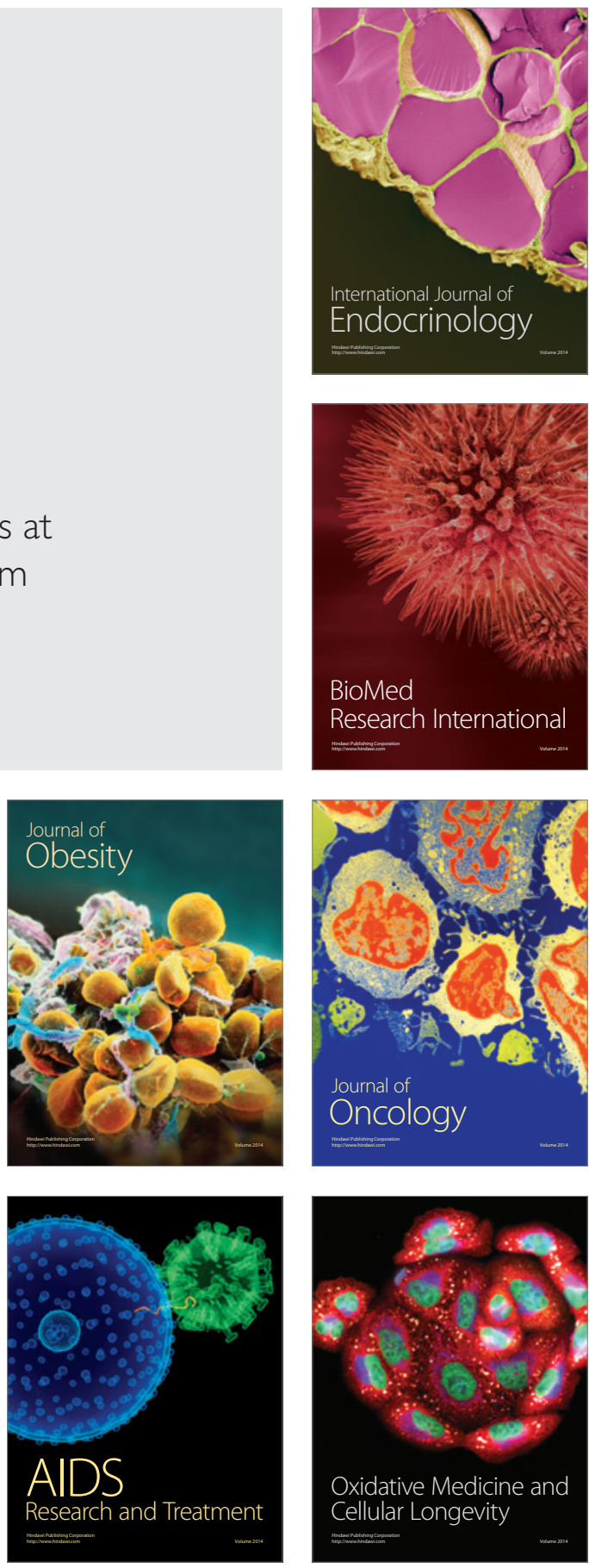